УДК 517.9:531.01

MSC 70E50

\title{
MATHEMATICAL MODEL OF A SUPERCONDUCTING MAGNETIC SUSPENSION IN ZERO GRAVITY
}

\author{
S. S. Zub ${ }^{1}$, I. V. Kyrychenko ${ }^{2}$, V. S. Lyashko ${ }^{1}$, I. G. Yaloveha ${ }^{3}$ \\ ${ }^{1}$ National Scientific Centre «Institute of Metrology», Kharkiv, Ukraine, E-mail: \\ stanislav.zub@metrology.kharkov.ua,v.s.lyashko@gmail.com \\ ${ }^{2}$ Robotics Design Bureau, Kyiv, Ukraine, E-mail: main@robotics.run \\ 3 Simon Kuznets Kharkiv National University of Economics, Kharkiv, Ukraine, E-mail: \\ yalovegaira@gmail.com
}

\section{МАТЕМАТИЧНА МОДЕЛЬ НАДПРОВІДНОГО МАГНІТНОГО ПІДВІСУ В НЕВАГОМОСТІ}

\author{
С. С. Зуь ${ }^{1}$, І. В. КиРиченко ${ }^{2}$, В. С. Ляшко ${ }^{1}$, І. Г. ЯловегА ${ }^{3}$ \\ ${ }^{1}$ Національний науковий центр «Інститут метрології, Харків, Україна, E-mail: \\ stanislav.zub@metrology.kharkov.ua,v.s.lyashko@gmail.com \\ ${ }^{2}$ TOВ «Конструкторське Бюро Роботікс», Київ, Україна, E-mail: main@robotics.run \\ ${ }^{3}$ Харківський національний економічний університет імені Семена Кузнеця, Харків, \\ Україна, E-mail: yalovegaira@gmail.com
}

\begin{abstract}
Paper provides a research of the mathematical model of a superconducting magnetic suspension in zero gravity. The model consists of a special configuration of the superconducting inductors and uniform magnetic field. The stabilization of suspension in dependence of angle between the magnetic field induction vector and the axis of the inductance coil that is a suspended «free» rigid body is researched. Analysis of the model on stability of equilibrium is carried out and the conditions of spatial magnetic well existence providing the contactless confinement of a rigid body in zero gravity are found. KEYWORDS: magnetic suspension, spatial magnetic well, magnetic levitation, stability.
\end{abstract}

АнотАція. В роботі проводиться дослідження математичної моделі надпровідного магнітного підвісу в умовах невагомості. Модель складається з спеціальної конфігурації надпровідних котушок індуктивності та однорідного магнітного поля. Досліджується механізм стабілізації підвісу за кутовою змінною між вектором індукції магнітного поля та віссю котушки індуктивності, яка представляє собою «вільне» тверде тіло. Проведено аналіз моделі на стійкість рівноваги та знайдено умови існування просторової магнітної ями, яка забезпечує безконтактне утримання твердого тіла в умовах невагомості.

КлЮчовІ СловА: магнітний підвіс, просторова магнітна яма, магнітна левітація, стійкість. 


\section{ВСТуП}

Безконтактну статичну рівновагу тіл, які взаємодіють виключно далекодіючими силами, можна забезпечити лише при наявності в системі просторово протяжних магнітних тіл $[1,2]$. Пошук таких магнітних систем виникає в задачах магнітної левітації.

Зокрема, передумовою реалізації магнітної левітації в системах багатозв'язних надпровідних тіл є «ефект МПЯ».

Означення 1. Просторова магнітна яма - магнітна конфігурація тіл, в якій стійка просторова рівновага «вільного» твердого тіла або тіл реалізується виключно за рахунок магнітних сил. Отже, це рівновага, що не залежить від зміни орієнтації твердого тіла.

Означення 2. Не типова поведінка магнітної сили, коли сила змінює знак на інтервалі взаємодії - «феномен МПЯ» або «ефект МПЯ». Наприклад, така сила виникає при взаємодії двох ідеально провідних кілець у співвісному положенні за умови, що магнітні потоки в них різні [3].

Означення 3. Магнітна потенціальна яма (МПЯ) - магнітна конфігурація тіл, в якій стійка статична рівновага «вільного» твердого тіла (не має контакту з іншими тілами) або тіл реалізується виключно за рахунок магнітних сил.

У роботі $[4,5]$ було доведено, що конфігурація багатозв'язних надпровідних тіл, яка забезпечує стійкість рівноваги вільного надпровідного кільця за трьома взаємно перпендикулярними просторовими зсувами [1], не є достатньою для реалізації просторової магнітної ями та МПЯ.

Як видно з визначення, поняття просторової магнітної ями тісно пов'язане з поняттями МПЯ та магнітної левітації.

Означення 4. Магнітна левітація являе собою статичну або динамічну рівновагу, в якій магнітна сила врівноважує поле сили тяжіння (гравітаційну силу). Існує декілька видів магнітної левітації, яким відповідають різні механізми, що забезпечують стійкість рівноваги.

Покажемо, що просторова магнітна яма все ж таки може бути реалізована через стабілізацію підвісу по кутовій змінній за допомогою однорідного магнітного поля.

\section{1. МАТЕМАТИЧНА МОДЕЛЬ МАГНІТНОї СИСТЕМИ}

Розглянемо магнітну систему, що складається з чотирьох надпровідних кілець: три з яких є концентричними та лежать у фіксованих взаємно перпендикулярних площинах, а четверте надпровідне кільце $€$ «вільним» твердим тілом і розташоване на деякій відстані від них. Аналогічну конфігурацію розглянуто в роботі $[1$, с. $49-50]$, але там вважається, що «вільним» твердим тілом є конфігурація з трьох зв'язаних концентричних кілець, а четверте кільце навпаки $е$ фіксованим.

Зауважимо, що кільця не можна замінити контурами довільної форми, що лежать у взаємно перпендикулярних площинах, як це передбачено в 
роботі [1], тому що їхні взаємні індуктивності не обов'язково дорівнюють нулю.

Для дослідження запропонованої системи потрібно сформулювати математичну модель. Відомо, що рівняння для квазістаціонарних ланцюгів можуть бути розглянуті з точки зору лагранжового підходу. Для дослідження стійкості просторової рівноваги достатньо проаналізувати лише потенціальну енергію системи. В роботі [6], отримано узагальнений силовий потенціал, який залежить тільки від механічних координат - потенціальна енергія системи:

$$
V=\frac{1}{2} \sum_{\alpha, \beta} L_{\alpha \beta}^{-1} \Psi_{\alpha} \Psi_{\beta}-\frac{1}{2} \sum_{a, b} L_{a b}^{*} I_{a} I_{b}-\sum_{\alpha, b} \Gamma_{\alpha b} \Psi_{\alpha} I_{b}+\Pi\left(t, X_{I}\right),
$$

де $\Psi_{\alpha}, L_{\alpha \beta}-$ «заморожені» магнітні потоки, що відповідають надпровідним кільцям та взаємні індуктивності між відповідними кільцями (позначені індексами).

Так як в запропонованій системі наявні тільки надпровідні кільця (немає постійних магнітів та «теплих» котушок індуктивності), в формулі (1) відмінний від нуля буде лише перший доданок. Відповідно параметри такої системи будуть:

$$
\begin{gathered}
L_{\alpha \beta}^{-1}=\Delta^{-1}\left|\begin{array}{cccc}
\Delta_{1} & L_{3} L_{14} L_{24} & L_{2} L_{14} L_{34} & -L_{2} L_{3} L_{14} \\
L_{3} L_{14} L_{24} & \Delta_{2} & L_{1} L_{24} L_{34} & -L_{1} L_{3} L_{24} \\
L_{2} L_{14} L_{34} & L_{1} L_{24} L_{34} & \Delta_{3} & -L_{1} L_{2} L_{34} \\
-L_{2} L_{3} L_{14} & -L_{1} L_{3} L_{24} & -L_{1} L_{2} L_{34} & L_{1} L_{2} L_{3}
\end{array}\right|, \\
\Delta=L_{1} L_{2} L_{3} L_{4}-L_{2} L_{3} L_{14}^{2}-L_{1} L_{3} L_{24}^{2}-L_{1} L_{2} L_{34}^{2} ; \\
\Delta_{1}=L_{2} L_{3} L_{4}-L_{2} L_{34}^{2}-L_{3} L_{24}^{2} ; \\
\Delta_{2}=L_{1} L_{3} L_{4}-L_{1} L_{34}^{2}-L_{3} L_{14}^{2} ; \\
\Delta_{3}=L_{1} L_{2} L_{4}-L_{1} L_{24}^{2}-L_{2} L_{14}^{2} .
\end{gathered}
$$

Після підстановки параметрів в (1) потенціальна енергія системи має вид:

$$
V=\frac{\left(\left(L_{1} L_{2} L_{4}-L_{2} L_{14}^{2}-L_{1} L_{24}^{2}\right) \Psi_{3}^{2}-2 L_{1} L_{2} L_{34} \Psi_{3} \Psi_{4}+L_{1} L_{2} L_{3} \Psi_{4}^{2}\right)}{2 \Delta} .
$$

Як приклад просторової магнітної ями, у роботі [1, с. 49-51] пропонується спеціальний випадок конфігурації чотирьох контурів кільцевої форми. Тому детально розглянемо умови стійкості, враховуючи особливості геометрії саме чотирьохкільцевої конфігурації.

3 незначною втратою загальності будемо вважати, що $L_{1}=L_{2}=L_{S t}$, тоді вираз (2) істотно спрощується. Як вже відзначалось, з точністю до позначень ця формула збігається з формулою, отриманою в роботі $[1$, с. 49], і потенціальна енергія $V$ є функцією параметрів $L_{S t}, L_{3}, L_{4}, \Psi_{3}, \Psi_{4}$ і змінних $M_{1}, M_{2}, M_{3}$.

Градієнт і гессіан потенціальної енергії, як складної функції $x^{\mu}=x, y, z, \theta, \varphi$, мають вид:

$$
\frac{\partial V}{\partial x^{\mu}}=\frac{\partial V}{\partial M_{S}} \cdot \frac{\partial M_{S}}{\partial x^{\mu}}
$$




$$
\frac{\partial^{2} V}{\partial x^{\mu} \partial x^{\nu}}=\frac{\partial^{2} V}{\partial M_{S} \partial M_{K}} \cdot \frac{\partial M_{S}}{\partial x^{\mu}} \cdot \frac{\partial M_{K}}{\partial x^{\nu}}+\frac{\partial V}{\partial M_{S}} \cdot \frac{\partial^{2} M_{S}}{\partial x^{\mu} \partial x^{\nu}},
$$

де $S, K=1,2,3$ - індекси кілець.

Використовуємо стандартну домовленість щодо підсумовування повторюваних індексів.

Відповідно до формул (3), (4) аналіз стійкості системи можна розділити на два етапи: знаходження мінімуму потенціальної енергії $V$ як функції взаємних індуктивностей $M_{S}$ і дослідження поведінки функцій $M_{S}$ як функцій узагальнених координат $x^{\mu}$.

У точці мінімуму функції $V\left(M_{1}, M_{2}, M_{3}\right)$ градієнт $V$ по $M_{S}$ повинен дорівнювати нулю. Умови $M_{1}=M_{2}=0$ природно випливають з ідеї запропонованої конфігурації (наприклад, це завжди виконується в разі співвісного положення 3-го і 4-го кілець) і автоматично приводять до того, що перші дві компоненти градієнта дорівнюють нулю. Математично це обумовлено тим, що функція $V$ залежить від $M_{1}, M_{2}$ через квадрати цих величин і тоді $\partial V / \partial M_{1} \sim M_{1}$, a $\partial V / \partial M_{2} \sim M_{2}$ i, отже,

$$
\frac{\partial V}{\partial M_{1}}=\frac{\partial V}{\partial M_{2}}=0
$$

тому в наступних викладеннях усюди приймаємо $M_{1}=M_{2}=0$.

Останній компонент градієнта знаходиться прямим обчисленням, причому в цьому випадку потенціальної енергія даної системи збігається з більш простим виразом для потенціальної енергії двокільцевої системи:

$$
\frac{\partial V}{\partial M_{3}}=-\frac{\left(L_{3} \Psi_{4}-M_{3} \Psi_{3}\right)\left(L_{4} \Psi_{3}-M_{3} \Psi_{4}\right)}{\left(L_{3} L_{4}-M_{3}^{2}\right)^{2}} .
$$

Те, що струм у базовому кільці дорівнюе нулю, є еквівалентним умові

$$
L_{4} \Psi_{3}-M_{3} \Psi_{4}=0,
$$

що відповідно до (6) приводить до виконання $\partial V / \partial M_{3}=0$.

У такий спосіб показано, що (4) дійсно є необхідними умовами мінімуму функції $V\left(M_{1}, M_{2}, M_{3}\right)$. Достатні умови мінімуму визначаються поведінкою гессіана функції $V\left(M_{1}, M_{2}, M_{3}\right)$. Знову використовуючи ту обставину, що функція $V$ залежить від $M_{1}, M_{2}$, через квадрати цих величин знаходимо

$$
\frac{\partial^{2} V}{\partial M_{S} \partial M_{K}}=0
$$

якщо $S \neq K$, де $S, K=1,2,3$.

Отже, гессіан $V$ є діагональною матрицею, ненульові елементи якої знаходять безпосередньо диференціюванням, використовуючи зазначені вище властивості функції $V$ :

$$
\begin{aligned}
& \frac{\partial^{2} V}{\partial M_{1}^{2}}=\frac{\partial^{2} V}{\partial M_{2}^{2}}=\frac{2 \Psi_{4}^{2}}{L_{S t} L_{4}^{2}}>0 \\
& \frac{\partial^{2} V}{\partial M_{3}^{2}}=\frac{\Psi_{4}^{2}}{L_{4}} \frac{1}{L_{3} L_{4}-M_{3}^{2}}>0 .
\end{aligned}
$$


Потенціальна енергія цієї системи (2), яку розглядають як функцію трьох незалежних перемінних $M_{S}=L_{4 S}(S=1,2,3$ - індекси кілець), як зазначає Козоріз, має чіткий мінімум за умов, коли:

$$
M_{3}=L_{4} \Psi_{3} \Psi_{4}^{-1}, M_{1}=M_{2}=0 .
$$

3 (8)-(10) випливає, що гессіан від $V$ є позитивно визначеною матрицею в точці (11), і тому в даній точці досягають строгого мінімуму функції $V\left(M_{1}, M_{2}, M_{3}\right)$.

Перейдемо до дослідження поведінки потенціальної енергії $V$ як функції узагальнених координат $x^{\mu}$ у точці $x_{0}^{\mu}=\left(0,0, z_{0}, 0,0\right)$, визначеної умовами (11). Дана точка знаходиться на осі $z$, а $\dddot{1}$ відстань від базового кільця знаходимо з умови (7), що збігається з умовою одномірного мінімуму потенціальної енергії двокільцевої системи:

$$
M_{3}\left(z_{0}\right)=L_{4} \Psi_{3} / \Psi_{4}
$$

3 урахуванням знайденої структури гессіана і рівності нулю градієнта функції $V\left(M_{1}, M_{2}, M_{3}\right)$ формула (4) за умов (11) приймає вид:

$$
\begin{gathered}
\frac{\partial^{2} V}{\partial x^{\mu} \partial x^{\nu}}=\frac{\partial^{2} V}{\left(\partial M_{1}\right)^{2}} \frac{\partial M_{1}}{\partial x^{\mu}} \frac{\partial M_{1}}{\partial x^{\nu}}+\frac{\partial^{2} V}{\left(\partial M_{2}\right)^{2}} \frac{\partial M_{2}}{\partial x^{\mu}} \frac{\partial M_{2}}{\partial x^{\nu}}+ \\
\frac{\partial^{2} V}{\left(\partial M_{3}\right)^{2}} \frac{\partial M_{3}}{\partial x^{\mu}} \frac{\partial M_{3}}{\partial x^{\nu}} .
\end{gathered}
$$

Досліджуємо в точці $x_{0}^{\mu}$ структуру матриці Якобі $\partial M_{S} / \partial x^{\mu}$, що входить у вираз (12). Більшість елементів цієї матриці дорівнюють нулю у зв'язку з особливими властивостями взаємної індуктивності двох кільцевих струмів і спеціальною конфігурацією даної магнітної системи.

Нехай $\vec{m}$ і $\vec{n}$ - нормалі до площин кілець, а $\vec{R}_{0}$ - вектор, що з'єднує центри кілець. Тоді у разі виконання умов ортогональності $(\vec{m}, \vec{n})=0 \mathrm{i}$ $\left(\vec{m}, \vec{R}_{0}\right)=0$ взаємна індуктивність таких кілець дорівнюе нулю. Якщо малий приріст деякої узагальненої координати (у випадку фіксованих значень інших) не приводить до порушення цих умов, то відповідна частинна похідна взаємної індуктивності дорівнює нулю. Розглянемо, наприклад, похідну $\partial M_{2} / \partial \theta$. Через те, що в точці $x_{0}^{\mu}$, яка нас цікавить, координата $\varphi=0$, то збільшенню $\theta$ відповідає обертання вільного кільця, за якого його нормаль робить поворот у площині $x z$ навколо закріпленого на осі $z$ центра. У такому разі нормаль вільного кільця залишається ортогональною нормалі 2-го стабілізатора, а вектор, що з'єднує їхні центри, не змінюється, тому $\partial M_{2} / \partial \theta=0.3$ іншого боку $\partial M_{1} / \partial \theta \neq 0$ через те, що в разі такого ж обертання вільного кільця порушується умова ортогональності між його площиною і площиною 1-го стабілізатора (i, відповідно, нормалей до них). Те, що чотири похідні $\partial M_{3} / \partial x^{\mu}$ дорівнюють нулю, випливає з властивості осьової симетрії; той же результат отримано безпосереднім обчисленням у роботі [2, с.163]. Остаточно структура матриці Якобі $\partial M_{S} / \partial x^{\mu}$ має вид:

$$
\left|\begin{array}{ccccc}
\partial M_{1} / \partial x & 0 & 0 & \partial M_{1} / \partial \theta & 0 \\
0 & \partial M_{2} / \partial y & 0 & 0 & 0 \\
0 & 0 & \partial M_{3} / \partial z & 0 & 0
\end{array}\right| .
$$


3 урахуванням (12), (13) у гессіані $\partial^{2} V / \partial x^{\mu} \partial x^{\nu}$ відмінними від нуля залишаються тільки діагональні елементи і компонент $H_{14}=H_{41}$ :

$$
\begin{gathered}
\frac{\partial^{2} V}{\partial x^{2}}=\frac{\partial^{2} V}{\left(\partial M_{1}\right)^{2}}\left(\frac{\partial M_{1}}{\partial x}\right)^{2}=H_{11} ; \\
\frac{\partial^{2} V}{\partial y^{2}}=\frac{\partial^{2} V}{\left(\partial M_{2}\right)^{2}}\left(\frac{\partial M_{2}}{\partial y}\right)^{2}=H_{22} ; \\
\frac{\partial^{2} V}{\partial z^{2}}=\frac{\partial^{2} V}{\left(\partial M_{3}\right)^{2}}\left(\frac{\partial M_{3}}{\partial z}\right)^{2}=H_{33} ; \\
\frac{\partial^{2} V}{\partial \theta^{2}}=\frac{\partial^{2} V}{\left(\partial M_{1}\right)^{2}}\left(\frac{\partial M_{1}}{\partial \theta}\right)^{2}=H_{44} ; \\
\frac{\partial^{2} V}{\partial x \partial \theta}=\frac{\partial^{2} V}{\partial \theta \partial x}=\frac{\partial^{2} V}{\left(\partial M_{1}\right)^{2}}\left(\frac{\partial M_{1}}{\partial x} \frac{\partial M_{1}}{\partial \theta}\right)=H_{14} .
\end{gathered}
$$

Відповідно, інші компоненти гессіана дорівнюють нулю. Умови стійкості для матриці гессіана такого виду відомі:

$$
H_{11}>0 ; H_{22}>0 ; H_{33}>0 ; H_{11} \cdot H_{44}>H_{14}^{2} .
$$

Перші три з них виконуються у виді співвідношень $(9,10) .3$ (14) маємо:

$$
H_{11} \cdot H_{44}-H_{14}^{2}=\left[\frac{\partial^{2} V}{\partial M_{1}^{2}}\right]^{2} \cdot\left(\left[\frac{\partial M_{1}}{\partial x}\right]^{2} \cdot\left[\frac{\partial M_{1}}{\partial \theta}\right]^{2}-\left[\frac{\partial M_{1}}{\partial x} \cdot \frac{\partial M_{1}}{\partial \theta}\right]^{2}\right)=0
$$

а це означає, що одна з умов стійкості не виконується.

Мінор матриці (13) за змінними $y, z, \theta$ має детермінант, відмінний від нуля. За теоремою про неявну функцію [7, с. 453-455] це означає, що змінні $y, z, \theta$ локально можна бути виразити через змінні $x$ і $\varphi$, які в такому випадку розглядають як параметри двовимірної поверхні, що задовольняє умовам (11). Отже, маємо такий складний рух кільця, який виводить його із знайденої точки рівноваги, не змінюючи потенціальної енергії системи, тобто дана конфігурація, запропонована в роботі [1, с. 49], не забезпечує ані просторову магнітну яму, ані МПЯ.

\section{2. МАТЕМАТИЧНА МОДЕЛЬ СИСТЕМИ З ОДНОРІДНИМ МАГНІТНИМ ПОЛЕМ}

Проте, у розглянутій системі поряд з необхідними виконуються три з чотирьох достатніх умов стійкої рівноваги, а четверте носить байдужий характер, тобто відсутніми є як зворотні сили, так і сили, що приводять до розвитку нестійкості. Тому розглянута конфігурація може бути відправною точкою для моделювання просторової магнітної ями.

Нижче буде показано, що зовнішне однорідне магнітне поле, діючи вздовж осі $z$, здатне деформувати умови байдужої рівноваги (16) у напрямку позитивної визначеності, а оскільки воно є незначним за величиною, тому не змінюе характеру перших 3-х умов (15). Помітимо, що, на відміну від системи [1, с. 119], як вільне тіло розглядаємо вільне кільце, а не систему 3-х механічно зв'язаних кілець; у відсутності магнітного поля обидва підходи є еквівалентними, але в присутності зовнішнього однорідного магнітного 
поля запропонований підхід має перевагу за рахунок спрощення розрахунків основних характеристик системи. В роботі [1] не розглядається така система в зовнішньому однорідному магнітному полі.

Відомо, що однорідне магнітне поле робить стабілізуючий вплив по куту на контури з постійним струмом. Розглянемо, який вплив воно робить на надпровідний струмовий виток. Особливість такої системи пов'язана з ідеальною провідністю надпровідного витка, а значить постійною величиною буде загальний потік через контур, а не струм у контурі.

Для довільного надпровідного контуру в зовнішньому магнітному полі сумарний потік через контур визначається за формулою [6, с. 93]:

$$
L I+\Psi_{e}=\text { const } \equiv \Psi_{0} .
$$

Виразимо струм у надпровідному контурі через потоки й індуктивність: $I=(\Psi-\Phi) / L$; тоді вираз магнітної енергії через потоки виходить підстановкою струму $I$ в формулу [6, (5), с. 91]:

$$
V=\frac{\Psi^{2}-\Phi^{2}}{2 L}
$$

де $V$ - енергія контуру в магнітному полі;

$\Phi=B_{0} S \cos \theta-$ потік зовнішнього однорідного поля через контур;

$S$ - площа контуру;

$\theta$ - кут між вектором індукції магнітного поля $\left(\vec{B}_{0}\right)$ і нормаллю до площини контуру.

Таким чином, залежність енергії від кута $\theta$ має вид:

$$
V=\frac{1}{2 L}\left(\left(\Psi^{2}-\Phi_{0}^{2}\right)+\Phi_{0}^{2} \sin ^{2} \theta\right)
$$

де $\Phi_{0}=\left.\Phi\right|_{\theta=0}$.

3 (17) випливає, що енергія надпровідного контуру як функція кута $\theta$ на проміжку $\theta \in[0, \pi]$ має два мінімуми (два положення рівноваги), коли $\theta=0$ i $\theta=\pi$, тоді як у випадку контуру із заданим струмом, маємо лише одне стійке положення рівноваги $(\theta=0)$.

Розглянемо тепер нашу чотирьохкільцеву систему в присутності зовнішнього однорідного магнітного поля. Одержимо вираз магнітної енергії нашої системи через потоки; як і у випадку одного контуру це можна зробити за допомогою формули (2) або $[6,(5)$, с.91] та співвідношенням $[6$, c.93]:

$$
\sum_{k} L_{i k} I_{k}+\Psi_{i}^{(e)}=\Psi_{i 0}
$$

де $\Psi_{i}^{(e)}$ - потік зовнішнього поля через $i$-й контур; $\Psi_{i 0}$ - сумарний потік через поверхню.

$$
V=\frac{1}{2} \frac{\Psi_{3}^{2}-\Phi_{3}^{2}}{L_{3}}+\frac{1}{2} \frac{\left(\Psi_{4}-\frac{M_{3}}{L_{3}} \Psi_{3}\right)^{2}-\left(\Phi_{4}-\frac{M_{3}}{L_{3}} \Phi_{3}\right)^{2}}{L_{4}-\frac{M_{1}^{2}-M_{2}^{2}}{L_{S t}}-\frac{M_{3}^{2}}{L_{3}}} .
$$

Помітимо, що перший доданок ніяк не впливає на динаміку системи через те, що його внесок в енергію системи є константою. Потоки $\Phi_{3}$ і $\Phi_{4} \in$ прямо 
пропорційними зовнішньому магнітному полю, тому потенціальна енергія і її похідні квадратично залежать від $B_{0}$ і при невеликих значеннях $B_{0}$ мало відрізняються від відповідних величин за відсутності зовнішнього поля.

Потенціальна енергія такої системи є функцією 4-х змінних $M_{1}, M_{2}, M_{3}$, $\Phi_{4}$. Зовнішне поле $\epsilon$ спрямованим по осі $z$ і тому не порушує симетрію системи; єдина додаткова змінна $\Phi_{4}$, яка здатна вплинути на стійкість системи, залежить від $\theta$. Тому знову будемо шукати положення стійкості при співвісному положенні 3-го і 4-го кілець. При наявності зовнішнього поля градієнт потенціальної енергії має вид:

$$
\frac{\partial V}{\partial x_{\mu}}=\frac{\partial V}{\partial M_{S}} \frac{\partial M_{S}}{\partial x_{\mu}}+\frac{\partial V}{\partial \Phi_{4}} \frac{\partial \Phi_{4}}{\partial x_{\mu}} .
$$

Аналогічно до випадку без поля, шукаємо нуль сили на осі $z$. На осі градієнт $\partial \Phi_{4} / \partial x_{\mu}=0$, та $\partial M_{3} / \partial z \neq 0$, тому необхідна умова стійкості знову $\partial V / \partial M_{3}=0$. В екстремумі матриця гессіана має таку структуру:

$$
\begin{gathered}
\frac{\partial^{2} V}{\partial x^{\mu} \partial x^{\nu}}=\frac{\partial^{2} V}{\partial M_{1}^{2}} \frac{\partial M_{1}}{\partial x^{\mu}} \frac{\partial M_{1}}{\partial x^{\nu}}+\frac{\partial^{2} V}{\partial M_{2}^{2}} \frac{\partial M_{2}}{\partial x^{\mu}} \frac{\partial M_{2}}{\partial x^{\nu}}+ \\
\frac{\partial^{2} V}{\partial M_{3}^{2}} \frac{\partial M_{3}}{\partial x^{\mu}} \frac{\partial M_{3}}{\partial x^{\nu}}+\frac{\partial V}{\partial \Phi_{4}} \frac{\partial^{2} \Phi_{4}}{\partial x^{\mu} \partial x^{\nu}} .
\end{gathered}
$$

Враховуючи розглянуту структуру матриці Якобі $\partial M_{S} / \partial x_{\mu}$, в матриці гессіана (18) не нульовими будуть такі компоненти:

$$
\begin{gathered}
\frac{\partial^{2} V}{\partial x^{2}}=\frac{\partial^{2} V}{\left(\partial M_{1}\right)^{2}}\left(\frac{\partial M_{1}}{\partial x}\right)^{2}=H_{11} \\
\frac{\partial^{2} V}{\partial y^{2}}=\frac{\partial^{2} V}{\left(\partial M_{2}\right)^{2}}\left(\frac{\partial M_{2}}{\partial y}\right)^{2}=H_{22} ; \\
\frac{\partial^{2} V}{\partial z^{2}}=\frac{\partial^{2} V}{\left(\partial M_{3}\right)^{2}}\left(\frac{\partial M_{3}}{\partial z}\right)^{2}=H_{33} ; \\
\frac{\partial^{2} V}{\partial \theta^{2}}=\frac{\partial^{2} V}{\left(\partial M_{1}\right)^{2}}\left(\frac{\partial M_{1}}{\partial \theta}\right)^{2}+\frac{\partial V}{\partial \Phi_{4}} \frac{\partial^{2} \Phi_{4}}{\partial \theta^{2}}=H_{44} ; \\
\frac{\partial^{2} V}{\partial x \partial \theta}=\frac{\partial^{2} V}{\partial \theta \partial x}=\frac{\partial^{2} V}{\left(\partial M_{1}\right)^{2}}\left(\frac{\partial M_{1}}{\partial x} \frac{\partial M_{1}}{\partial \theta}\right)=H_{14}=H_{41} .
\end{gathered}
$$

Структура матриці гессіана буде такою самою, як і для випадку без поля (14). Безпосередньо з обчислень отримуємо вирази для $\partial^{2} V / \partial M_{1}^{2}$ та $\partial^{2} V / \partial M_{2}^{2}$ :

$$
\begin{aligned}
\frac{\partial^{2} V}{\partial M_{1}^{2}} & =\frac{\left(L_{3} \Psi_{4}-M_{3} \Psi_{3}\right)^{2}-\left(L_{3} \Phi_{4}-\Phi_{3} M_{3}\right)^{2}}{L_{1}\left(L_{3} L_{4}-M_{3}^{2}\right)^{2}} \\
\frac{\partial^{2} V}{\partial M_{2}^{2}} & =\frac{\left(L_{3} \Psi_{4}-M_{3} \Psi_{3}\right)^{2}-\left(L_{3} \Phi_{4}-\Phi_{3} M_{3}\right)^{2}}{L_{2}\left(L_{3} L_{4}-M_{3}^{2}\right)^{2}}
\end{aligned}
$$

За умови малості $B_{0}$ виконуються нерівності

$$
\frac{\partial^{2} V}{\partial M_{S}^{2}}>0, S=1,2
$$


Бачимо, що з виразів (19)-(21), можна отримати максимальне значення $B_{0}$, вище за яке стійкість втрачається.

Коли $M_{1}=M_{2}=0$ маємо

$$
\frac{\partial V}{\partial M_{3}}=\frac{\left(L_{3} \Psi_{4}-M_{3} \Psi_{3}\right)\left(M_{3} \Psi_{4}-L_{4} \Psi_{3}\right)-\left(L_{3} \Phi_{4}-M_{3} \Phi_{3}\right)\left(M_{3} \Phi_{4}-L_{4} \Phi_{3}\right)}{\left(L_{3} L_{4}-M_{3}^{2}\right)^{2}} .
$$

Будемо аналізувати умову $\partial V / \partial M_{3}=0$. Спочатку розглянемо систему без поля при $B_{0}=0\left(\Phi_{4}=0, \Phi_{3}=0\right)$; тоді рішення для $z_{0}$ отримаємо з рівняння:

$$
L_{4} \Psi_{3}^{(0)}-M_{3} \Psi_{4}^{(0)}=0 ;\left(M_{3}^{(0)}=M_{3}\left(z_{0}\right)=M_{3}\right) .
$$

Для малого значення $B_{0}$ шукаємо рішення $\partial V / \partial M_{3}=0$ для тих самих значень $z_{0}$ та $\Psi_{4}=\Psi_{4}^{(0)}$, а $\Psi_{3}=\Psi_{3}^{(0)}+\delta \Psi_{3}$ відрізняється від величини при відсутності поля на малу величину

$$
\delta \Psi_{3} \approx-\frac{\left(L_{3} \Phi_{4}-M_{3} \Phi_{3}\right) \cdot\left(M_{3} \Phi_{4}-L_{4} \Phi_{3}\right)}{\Psi_{4}^{(0)}\left(L_{3} L_{4}-M_{3}^{2}\right)} .
$$

Таким чином, необхідна умова для стійкості може бути виконана для системи з полем при тому самому положенні, що і у випадку без поля, якщо вибрати потік базового кільця використовуючи формулу (22).

Так як у випадку без поля $\partial^{2} V / \partial M_{3}^{2}>0$, тому, як вже було зазначено, через безперервність, дана умова виконується і при малих значеннях $B_{0}$.

Вираз $\partial^{2} V / \partial M_{S}^{2}$ можемо безпосередньо отримати з формул для випадку без поля, де $\Phi_{4}=\Phi_{3}=0$, так як залежність від $\Phi_{3}$ та $\Phi_{4}$ аналогічна до $\Psi_{3}$ та $\Psi_{4}$.

Достатні умови стійкості (15) вимагають виконання

$$
\frac{\partial^{2} V}{\partial M_{1}^{2}} \frac{\partial V}{\partial \Phi_{4}}\left(\frac{\partial M_{1}}{\partial x}\right)^{2} \frac{\partial^{2} \Phi_{4}}{\partial \theta^{2}}>0
$$

враховуючи (21) умову (23) можемо переписати:

$$
\frac{\partial V}{\partial \Phi_{4}} \frac{\partial^{2} \Phi_{4}}{\partial \theta^{2}}>0
$$

В положенні співвісності

$$
\frac{\partial V}{\partial \Phi_{4}}=-\frac{\left(L_{3} \Phi_{4}-M_{3} \Phi_{3}\right)}{2\left(L_{3} L_{4}-M_{3}^{2}\right)} .
$$

Отже, з (24), (25) отримаємо

$$
B_{0}\left(L_{3} \Phi_{4}-M_{3} \Phi_{3}\right)>0
$$

де $\Phi_{4}=\pi r_{4}^{2} B_{0}$ та $\Phi_{3}=\pi r_{3}^{2} B_{0}$.

Бачимо, що (26) не залежить від напрямку та $B_{0}$, таким чином маємо

$$
\kappa^{2} L_{3}>M_{3},
$$

де $\kappa=r_{3} / r_{4}$.

Таким чином, у випадку наявності однорідного магнітного поля система здобуває стійкість. Знайдена магнітна конфігурація являє приклад просторової магнітної ями, яка цілком відповідає визначенню, даному у вступі. 


\section{ЛIтеРАТУРА}

1. Kozorez V. V. Dynamical systems of magnetically interacting free bodies. Kiev: Naukova Dumka publ., 1981. 140 p. (In Russian)

2. Mihalevich V. S., Kozorez V. V., Rashkovan V. M., et al. Magnetic potential well - effect of stabilization superconductive dynamic systems. Kiev: Naukova Dumka publ., 1991. 336 p. (In Russian)

3. Kozorez V. V., Kolodeev I. D., Kryukov M. I. et al. On potential well of magnetic interaction of ideal current loops. Dokl. AN USSR., Ser. A., 1975. No. 3. P. 248249. (In Russian)

4. Demutskiy V. P., Zub S. S., Rashkovan V. M. Stability analysis of static equilibrium in a system of three rigidly coupled superconducting coils and free superconducting coil. Visn. Khark. Univ., Ser. Phys. «Nuclei, Particles, Fields». 1999. No. 443. P. 34-40. (In Russian)

5. Zub S. S. The influence of superconducting elements topology on stability of static equilibrium of the free magnetic rigid body: Author's abstract. dis. Cand. tech. Sciences: 01.05.02., V. M. Glushkov Institute of Cybernetics of the NAS of Ukraine. Kyiv. 2005. 23 p. (in Ukrainian)

6. Lyashko S. I., Zub S. S., Yalovega I. G., Lyashko V. S. Mathematical model of permanent magnets and superconducting coils interaction. Cybernetics and Systems Analysis. 2022. Vol. 58. No. 1. P. 90-97. (in Ukrainian)

7. Fikhtengolts G. M. Course of differential and integral calculus. Moscow: Nauka, 1966. Vol. 1. 607 p. (In Russian)

Надійшла: 15.12.2021 / Прийнята: 20.12.2021

\section{МАТЕМАТИЧЕСКАЯ МОДЕЛЬ СВЕРХПРОВОДЯЩЕГО МАГНИТНОГО ПОДВЕСА В НЕВЕСОМОСТИ}

\section{С. С. Зуь ${ }^{1}$, И. В. Кириченко ${ }^{2}$, В. С. ЛЯшко}

${ }^{1}$ Национальный научный центр «Институт метрологии», Харьков, Украина, E-mail: stanislav.zub@metrology.kharkov.ua, v.s.lyashko@gmail.com

${ }^{2}$ ООО «Конструкторское Бюро Роботикс», Киев, Украина, E-mail: main@robotics.run

${ }^{3}$ Харьковский национальный экономический университет имени Семена Кузнеца, Харьков, Украина, E-mail: yalovegaira@gmail.com

АннотАция. В работе проводится исследование математической модели сверхпроводящего магнитного подвеса в условиях невесомости. Модель состоит из специальной конфигурации сверхпроводящих катушек индуктивности и однородного магнитного поля. Исследуется механизм стабилизации подвеса по угловой переменной между вектором индукции магнитного поля и осью катушки индуктивности, представляющей подвешиваемое «свободное» твердое тело. Проведен анализ модели на устойчивость равновесия и найдены условия существования пространственной магнитной ямы, обеспечивающей бесконтактное удержание твердого тела в условиях невесомости.

КЛЮчЕВЫЕ СЛОВА: магнитный подвес, пространственная магнитная яма, магнитная левитация, устойчивость. 